\title{
PENGGUNAAN DAYA MESIN PENGGERAK KAPAL PUKAT CINCIN KM. MAESTRO
}

\author{
(Engine power driver purse seiner KM. Maestro)
}

\author{
Revols D Ch Pamikiran ${ }^{1}$ \\ ${ }^{1}$ Fakultas Perikanan dan Ilmu Kelautan, Universitas Sam Ratulangi, Manado, Sulawesi Utara.
}

\begin{abstract}
Salah satu faktor yang mempengaruhi efektivitas dan efisiensi adalah penggunaan tenaga mesin (HP) dalam kegiatan penangkapan ikan. Tujuan dari penelitian ini adalah untuk mengetahui hubungan antara mesin utama (HP) dan kecepatan kapal (v), mengestimasi kekuatan pendorong berdasarkan ukuran dan kecepatan kapal, serta menentukan kategori berdasarkan kecepatan kapal. Penelitian terhadap Kapal motor (KM) Maestro purse seine di Desa Kema III, Kabupaten Minahasa Utara, Sulawesí Utara memperlihatkan bahwa hubungan antara tenaga mesin (HP) dan kecepatan kapal (knot) mengikuti model persamaan matematis sebagai berikut: $\mathrm{v}(\mathrm{knot})=13,05-6322 * \exp (-0,000117 *(\mathrm{HP}) \wedge 1.715)$.dan (2). Hasil estimasi di lapangan menunjukkan bahwa kecepatan kapal (knot) berdasarkan jumlah putaran mesin (rpm) dan tenaga mesin (HP) yang mengkategorikan kapal kecepatan tinggi.

Kata kunci: mesin, horse power, kecepatan, kapal pukat cincin.

One of the factors that influence the effectiveness and efficiency of fishing activities is the use of power of the engine (HP) in fishing activities. The purpose of this study was to determine the relationship between the main engine (HP) and speed of the vessel ( $y$ ), and to estimate of propulsion power based on size and speed of the ship, as well as to identify the category based on her speed. The study on the Maestro purse seiner in Kema III village, North Minahasa regency, North Sulawesi, showed that the elationship between the power engine (HP) and speed of the ship (knots) followed a mathematical equation model: $\mathrm{v}($ knots $)=13.05-6322 * \exp (-0.000117 *(\mathrm{HP}) \wedge 1,715)$, and (2). The estimation in the field showed that ship speed (knots) based on the amount of the engine speed (rpm) and power engine (HP), could be categorized as high speed.
\end{abstract}

Keywords: engine, horse power (HP), speed, purser-seiner.

\section{PENDAHULUAN}

Kapal perikanan adalah kapal ataulatatrapung yang digunakan untuk menangkap ikan termasuk juga untuk survey dan eksplorasi sumberdaya hayati perairan (Anonimous, 1985). Abilite atau kemampuan kapal yang baik tentunya sangat diharapkan untuk dapat menunjang efektifitas dan efisiensi kegiatan penangkapan ikan, dan pada akhirnya akan memberikan dampak yang baik atau keuntungan bagi usaha perikanan itersendiri. Salah satu faktor yang mempengaruhie efektifitas dan efisiensi dari kapal adalah penggunaan daya (HP) dari mesin pendorong kapal (Pamikiran, 2009). Selanjutnya dinyatakan bahwa tentunya penggunaan daya mesin pendorong ini disesuaikan dengan ukuran, kecepatan, dan tujuan dari penggunaan kapal tersebut di lapangan. Hal ini semestinya dapat dilakukan secara cermat lewat suatu kajian, tetapi pada kenyataannya di lapangan masih banyak nelayan belum mengetahui hal ini. Lewat suatu kajian dapat diketahui keperluan daya mesin berdasarkan kebutuhan kecepatan kapal (kecepatan rendah, normal dan tinggi). Berdasarkan hal ini maka dilakukan suatu kajian untuk mengestimasi dan mengevaluasi penggunaan daya mesin penggerak dari salah satu kapal perikanan ya- itu KM. Maestro yang digunakan oleh nelayan pukat cincin di Desa Kema 3, Provinsi Sulawesi Utara.

Tujuan dari penelitian ini adalah mengetahui hubungan antara daya mesin penggerak (HP) dan kecepatan kapal (v); serta mengestimasi daya penggerak kapal berdasarkan ukuran dan kecepatan kapal, serta mengidentifikasi kategori kapal berdasarkan kecepatannya. Penelitian ini diharapkan dapat bermanfaat bagi perencanaan dan evaluasi terhadap efektifitas dan efisiensi penggunaan daya mesin dalam kaitannya dengan capaian kecepatan kapal yang diharapkan.

Instalasi tenaga penggerak utama kapal merupakan suatu (sistem) yang bekerja untuk memberikan daya dorong pada kapal sehingga kapal dapat bergerak maju atau mundur (Adji, 2005). Selanjutnya dikatakan daya yang disalurkan (PD) ke alat gerak kapal adalah berasal dari Daya Poros (PS), sedangkan Daya Poros sendiri bersumber dari Daya Rem (PB) yang merupakan daya luaran motor penggerak kapal. Ada beberapa pengertian mengenai daya yang sering digunakan dalam melakukan estimasi terhadap kebutuhan daya pada sistem penggerak kapal yaitu : tenaga penggerak (PE), tenaga dorong $(\mathrm{PT})$, tenaga disalurkan (PD), tenaga Shaft (PS), te- 
naga Brake (PB), dan tenaga terindikasi (PI). Breake Horse Power (BHP atau PB) adalah daya yang dikeluarkan oleh mesin dengan dipengaruhi beban mesin itu sendiri. Maksimum BHP adalah tenaga maksimal mesin yang diteruskan oleh mesin, biasanya pada rpm maksimum yang diijinkan. Ada beberapa cara untuk mengestimasi daya mesin penggerak kapal (Fyson, 1985; Attwod and Pengely, 1953; dan Suzuki, 1980) yaitu: berdasarkan pengukuran tahanan kapal secara langsung, penggunaan nilai koefisien Admiralty ${ }^{C}$, dan menggunakan Kurva hubungan antara $\mathrm{v} / \sqrt{\mathrm{L}}$ versus $\mathrm{BHP} / \Delta$.

Dalam penelitian ini akan digunakan cara estimasi berdasarkan kurva hubungan antara $\mathrm{V} / \sqrt{\mathrm{L}}$ dengan $\mathrm{BHP} / \Delta$, dengan model kurva sebagai berikut: $\mathrm{BHP} / \Delta$

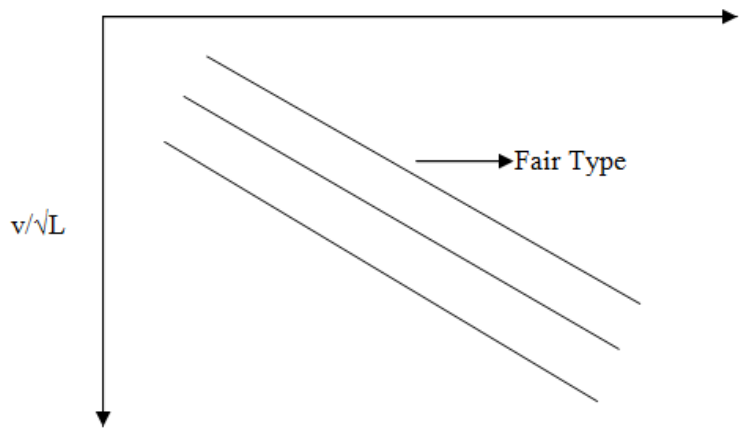

Gambar 1. Kurva hubungan $\mathrm{V} / \sqrt{ } \mathbf{L}$ dan $B H P / \triangle$ (model kurva telah disederhanakan).

Figure 1. Curves of $V / \sqrt{ } L$ and $B H P / \Delta$.

Dalam Suzuki (1980), dinyatakan tentang kategori kecepatan kapal berdasarkan ratio $k \downarrow \sqrt{L}(\forall$ dalam knot dan L dalam kaki) sebagai berikut: Speed length ratio $(\mathrm{SLR})=0,8$ (tergolong kécepatan rendah), SLR $=1,0$ (tergolong kecepatannormal), dan $\mathrm{SLR}=1,2$ (tergolong kecepatan tinggi). BHP merupakan salah satu indikator daya mesin penggerak selain indikator daya mesinyang lain seperti: SHP dan EHP (Fysson, 1985). Dan $\Delta$ (displacement tonase) adalah berat benaman kapal atau jumlah berat air yang dipindahkan sebagai akibat dari terbenamnya kapal di airr. Nilai ini diperoleh dari perkalian volume benaman kapal $\left(\mathrm{m}^{3}\right)$ dengan berat jenis air $(\rho)$ dimana kapal tersebut terbenam.

\section{C) METODE PENELITIAN}

Penelitian ini adalah penelitian hanya terbatas pada kajian, pembahasan dan kesimpulan untuk objek kapal yang diteliti (Sudjana, 1980). Objek dari penelitian ini adalah kapal pukat cincin KM. Maestro di Desa Kema 3, Kabupaten Minahasa Utara, Provinsi Sulawesi Utara.

Data spesifikasi kapal dan mesin penggerak kapal diperoleh dan dicatat dari dokumen yang ada di kapal yang meliputi gambar teknis kapal (lines- plane) beserta dengan ukuran-ukuran utama kapal (panjang, lebar dan dalam), draft atau tinggi benaman kapal sebagai dasar perhitungan volume benaman (displacement volume), spesifikasi teknis mesin penggerak, dan pengamatan terhadap jumlah putaran mesin (rpm) dengan Tacho-meter dalam kegiatan dinas kapal.

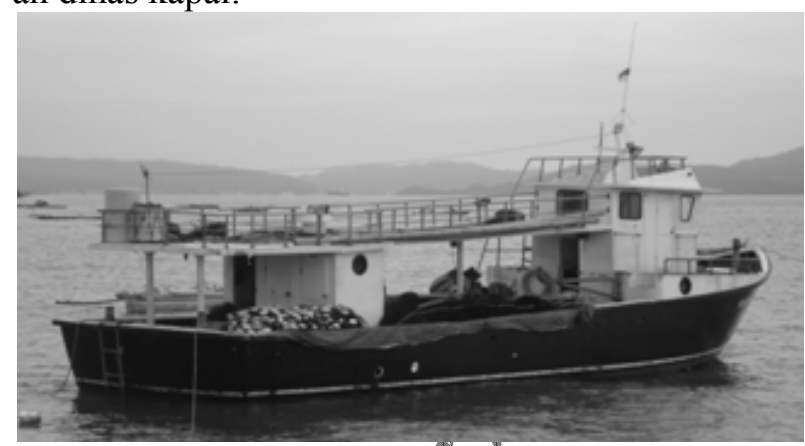

Gambar 2. Kapal Pukat Cincin KM. Maestro Figure 2. Purse seinen KM.Maestro

Ada beberapa analisis data yang dilakukan dalam penelitian inil yaitu perhitungan dan pemetaan daya mesin penggerak kapal (HP) berdasarkan pada kurva standar hubungan antara jumlah putaran mesin permenit dan daya mesin yang dihasilkan dalam satuan Kilo-watt (KW). Analisis SLR menggunakan cunnusan yang dikemukakan oleh Suzuki (1980) sebagai berikut: $S L R=v /(\sqrt{ } L)$, dimana $v=$ kecepatan Kapal (knot) dan $\mathrm{L}=$ panjang kapal (kaki).

Analisis hubungan dan pemetaan kurva BHP/ $\Delta$ dan $\mathrm{v} / \sqrt{\mathrm{L}}$ dilakukan berdasarkan data daya mesin penggerak, benaman kapal (displacement ton), dan ukuran panjang kapal (L). Kecepatan (v) kapal akan diestimasi berdasarkan ketiga data tadi dengan menggunakan kurva standar untuk keperluan ini dan dilaksanakan dalam kategori fair type berdasarkan pada kondisi bentuk tipe kapal yang diteliti. Selanjutnya dilakukan analisis untuk melihat model matematis hubungan antara daya penggerak (BHP) dan capaian kecepatan kapal (v) sehingga menjadi informasi yang lebih mudah dipahami dalam penggunaan kapal.

\section{HASIL DAN PEMBAHASAN}

KM. Maestro adalah kapal yang terbuat dari fiberglass, digunakan sebagai kapal ikan dengan alat tangkap pukat cincin, dan memiliki ukuran panjang $17 \mathrm{~m}$, lebar 4,45 $\mathrm{m}$ dan dalam 1,28 m, serta muatan kotor 26 GT. Kapal ini memiliki satu geladak, tanpa tiang, tanpa cerobong asap dan dilengkapi dengan mesin penggerak utama merek Yuchai model YC6A.

Tabel berikut ini menyajikan nilai dari rpm dan daya mesin (KW) dan horse-power (HP). Nilai 
ini diperoleh dari spesifikasi mesin kapal yang digunakan dan melalui konversi untuk daya.

Tabel 1. Nilai rpm dan daya mesin.

Table 1. Values of rpm and engine power.

\begin{tabular}{crr}
\hline \multirow{2}{*}{ Jumlah Putaran Mesin (rpm) } & \multicolumn{2}{c}{ Daya Mesin } \\
\cline { 2 - 3 } & KW & HP \\
\hline 900 & 60 & 80 \\
1100 & 90 & 121 \\
1300 & 128 & 172 \\
1500 & 150 & 201 \\
1700 & 165 & 221 \\
\hline
\end{tabular}

Hasil analisis hubungan jumlah putaran mesin (rpm) dan daya mesin yang dihasilkan (HP) adalah $\mathrm{HP}=\mathrm{a}+\mathrm{b}(\mathrm{rpm})+\mathrm{c}\left(\mathrm{rpm}^{\wedge} 2\right)+\mathrm{d}\left(\mathrm{rpm}^{\wedge} 3\right)$ dengan nilai estimator $\mathrm{a}=-2.8381 \mathrm{E}+002, \mathrm{~b}=5.5177 \mathrm{E}-001, \mathrm{c}=-$ 1.85944E-004, dan $\mathrm{d}=2.17803030 \mathrm{E}-008$. Pemetaan dari hubungan antara jumlah putaran mesin (rpm) dan daya mesin (HP) seperti pada Gambar 3.

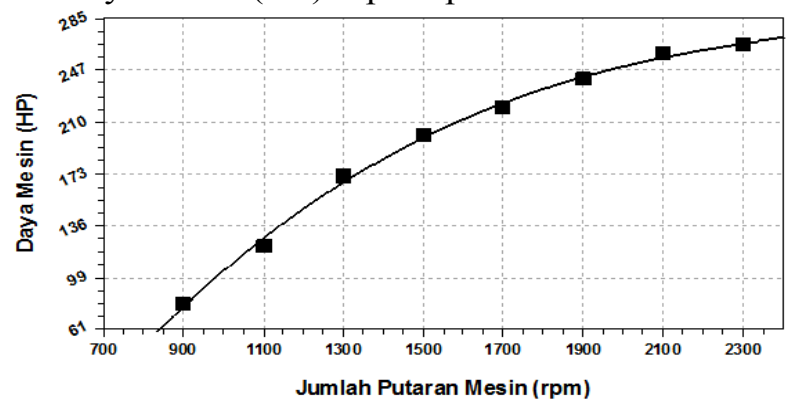

Gambar 3. Hubungan daya mesin dengan rpm.

Figure 3. Relationship of engine power with rpm.

Daya mesin penggerak (HP) kapal dan nilai estimasi kecepatan (knot) kapal dengan menggunakan kurva standar disajikan pada Tabel berikut ini.

Tabel 2. Daya mesin penggerak (F) kapal dan nilai estimasi kecepatan kapal(knot).

Table 2. Propulsion (HP) and the estimated value of boats speed (knots).

\begin{tabular}{lcccccccc}
\hline HP & 80 & 121 & 172 & 201 & 221 & 241 & 259 & 266 \\
\hline knot & 7,99 & 8,93 & 10,16 & 00,89 & 11,25 & 11,54 & 11,76 & 11,87 \\
\hline
\end{tabular}

Dari anallisis hubungan antara daya mesin penggerak-kapal (HP) dan kecepatan kapal (knot) diperoleh hubungan dengan Weibull model matematis sebagai berikut:

Z $=13,05-6,322 * \exp \left(-0.000117 *(\mathrm{HP})^{\wedge} 1.715\right)$.

Pemetaan diagram sebaran dan garis peramalan hubungan antara daya mesin dan kecepatan disajikan pada Gambar 4.

Jika interval putaran mesin (rpm) hasil pengamatan 1000-1400 rpm maka estimasi interval daya mesin adalah 104-184 HP, dan estimasi interval capaian kecepatan kapal adalah 8,5-10,5 knot. Klasifikasi kecepatan kapal berdasarkan pada SLR untuk kecepatan rendah, normal dan tinggi secara berturut- turut adalah: 5, 8, 7,26, dan 8,71 knot. Jika diperhatikan ternyata penggunaan nilai tertinggi putaran mesin (rpm) berdasarkan pengamatan di lapangan telah memberikan kontribusi dicapainya kategori kecepatan tinggi pada kapal yang diteliti. Jadi dapat disimpulkan bahwa rpm dan daya penggerak (HP) untuk mencapai kecepatan tinggi kapal telah terpenuhi. Disamping itu masih ada juga ekstra daya penggerak kapal dalam menghadapi situasi perairan yang tidak diharapkan seperti ombak, arus dan gelombang karena masih adanya peluang uptuk menambah jumlah putaran mesin (rpm) walaupun hanya dapat menghasilkan pertambahan daya mesin penggerak (HP) dan capaian kecepatan kapal yang sudah mulai berkurang. Hal inf berbeda dengan penggunaan daya mesin penggerak KM. Coelacanth dalam Pamikiran (2013), dimana penggunaan nilai tertinggi putaran mesie di lapangan belum dapat mencapai kategori kecepatan tinggi tetapi hanya mampu mencapai kecepatan normal kapal.

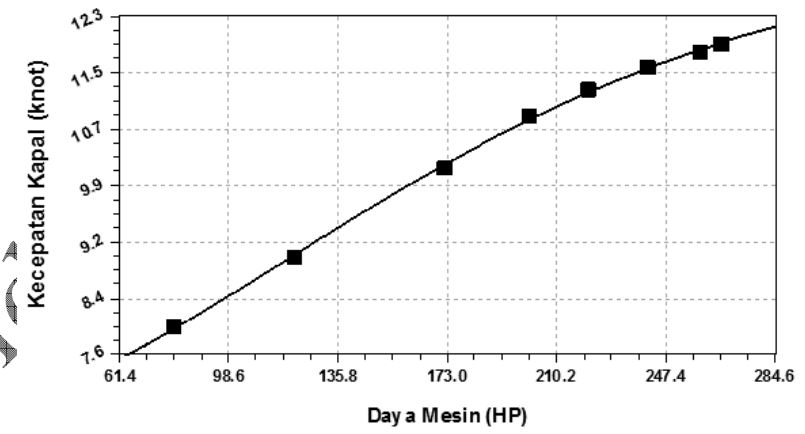

Gambar 4. Hubungan daya mesin dengan kecepatan kapal.

Figure 4. Relationship of engine power with speed.

\section{KESIMPULAN}

Hubungan antara daya mesin penggerak dan kecepatan kapal pukat cincin KM. Maestro, mengikuti model persamaan matematik:

$$
\mathrm{v}=13.05-6.322 * \exp \left(-0.000117 *(\mathrm{HP})^{\wedge} 1.715\right) \text {. }
$$

Hasil estimasi kecepatan kapal KM. Maestro berdasarkan penggunaan jumlah putaran mesin dan daya mesin penggerak dikategorikan sebagai kapal dengan kategori kecepatan tinggi.

\section{DAFTAR PUSTAKA}

Adji S. W., 2005. Engine Propeller Matching. Jakarta. 31 $\mathrm{h}$.

Undang-Undang Negara Republik Indonesia Nomor 9 Tahun 1985 Perikanan.

Atwood, E.L. O.B.E dan H.S. C.B. Pengelly, 1967. Teoritical Naval Architecture. Longmans. Great Britain. 302 p. 
Fyson J. (editor)., 1985. Design of Small Fishing Vessels. FAO. Fishing News Books Ltd. Farnham-SurreyEngland. $173 \mathrm{p}$.

Pamikiran, R.D.Ch. 2009. Penggunaan Daya Mesin Penggerak Kapal Pukat Cincin pada Beberapa Daerah di Sulawesi Utara. Pacific Journal. Vol.3 no.3. 419 421.
Pamikiran, R.D.Ch. 2013. Penggunaan Daya Mesin Penggerak KM Coelacanth di Kota Bitung. Propinsi Sulawesi Utara. Jurnal Ilmu dan Teknologi Perikanan Tangkap 1(3). FPIK-Unsrat. 103 - 106.

Suzuki, O., 1980. Handbook for Scientists and Technologist, Training Departement Southeast Asian Fisheries Development Center. 47 p.

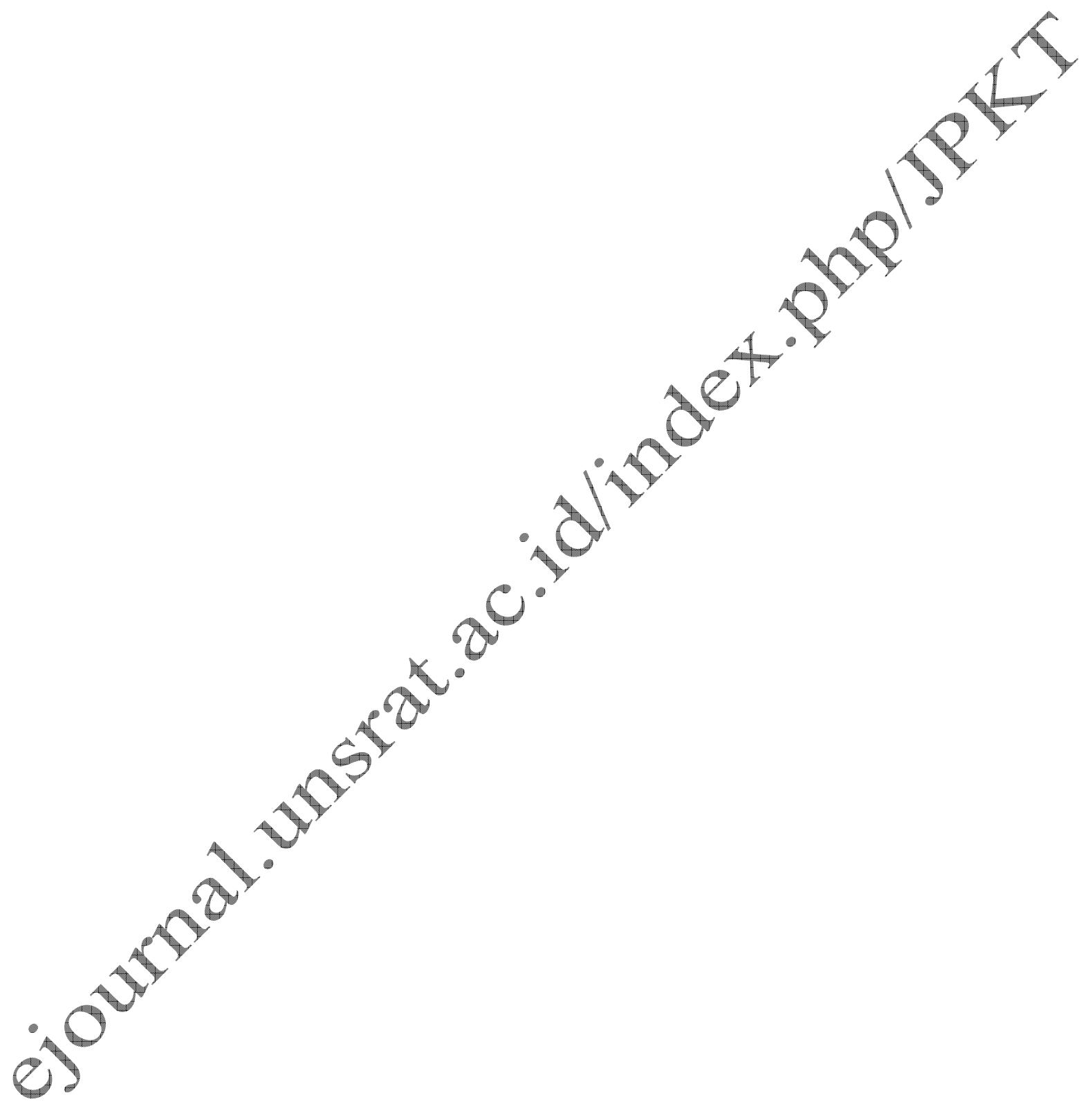

